\title{
Associations between psychosocial work environments and social capital: a multilevel analysis study in a Chinese context
}

\author{
Junling Gao', Jing Wang ${ }^{2}$, Denglai Yu², Junming Dai ${ }^{1}$, Yongkai Zhu ${ }^{1}$ and Hua Fu ${ }^{1 *}$
}

\begin{abstract}
Background: Understanding the determinants of social capital is the prerequisite to building social capital. However there was few studies to explore factors related to workplace social capital. We aim to examine associations between psychosocial work environments and social capital in a Chinese context through a cross-sectional study.

Methods: A cross-sectional study was conducted in Shanghai, China from December 2016 through March 2017. In total, 2380 workers from 32 workplaces were randomly sampled by a two-stage sampling procedure. Workplace social capital (WSC), psychosocial work environments (PWEs), and workplace Chinese Confucian values (CCVs), were assessed using validated and psychometrically tested measures. Multilevel ordinal regression models were used to examine the associations of WSC with individual- and workplace-level PWEs and workplace CCVs after controlling for individual socioeconomic characteristics.

Results: After controlling for individual socioeconomic characteristics, all individual-level PWEs (unstandardized coefficients [B] ranging from 0.280 to 2.467 ) were positively associated with WSC. Individual-level workplace CCVs had mixed associations with WSC — high individual levels of respect for authorities (B: $0.325 ; 95 \% \mathrm{Cl}: 0.134,0.516)$ and altruism (B: $0.347 ; 95 \% \mathrm{Cl}: 0.155,0.539)$ were associated with high WSC, while high individual levels of acceptance of authorities (B: $-0.214 ; 95 \% \mathrm{Cl}:-0.381,-0.046)$ and the mianzi rule (B: $-0.258 ; 95 \% \mathrm{Cl}:-0.435,-0.080)$ were associatecd with low WSC. No workplace-level variable was associated with WSC.

Conclusion: These findings suggest that workplace social capital associates with multiple factors. Psychosocial work environments and cultural context are important in understanding variations in workplace social capital between individuals.
\end{abstract}

\section{Background}

Social capital is defined as features of social organizationincluding networks, norms, and social trust-that facilitate coordination and cooperation for mutual benefit [1]. In the public health literature, social capital is viewed as a feature not only of social context but also of the individual actors living within the social context [2] and has always been measured at both the micro- (individual) and macro-level (community, workplace) in empirical studies. Long working

\footnotetext{
* Correspondence: hfu@fudan.edu.cn

'School of Public Health, Fudan University; Fudan Health Communication

Institute, PO Box 248, 138 Yixueyuan Road, Shanghai 200032, China

Full list of author information is available at the end of the article
}

hours have become the culture of many workplaces [3], where people are typically exposed to a reasonable amount of social relationships and day-to-day interactions. Thus, the workplace might be a dominant resource for social capital compared with the neighborhood and community. Workplace social capital (WSC) was defined as the shared values, attitudes, and norms of trust and reciprocity as well as practices of collective action in workplace [4]. WSC could affect health via processes of informal social control, social cohesion, maintenance of healthy norms and reinforcing healthy behaviours, and the provision of access to social support $[4,5]$. A growing body of research has shown

(c) The Author(s). 2018 Open Access This article is distributed under the terms of the Creative Commons Attribution 4.0 International License (http://creativecommons.org/licenses/by/4.0/), which permits unrestricted use, distribution, and reproduction in any medium, provided you give appropriate credit to the original author(s) and the source, provide a link to the Creative Commons license, and indicate if changes were made. The Creative Commons Public Domain Dedication waiver (http://creativecommons.org/publicdomain/zero/1.0/) applies to the data made available in this article, unless otherwise stated. 
that low WSC is associated with unhealthy behaviors [611], poor mental health [12-15], and high mortality [16].

Researchers [17, 18] have suggested building social capital as a strategy for health promotion within and between populations. However, there have been relatively few public health interventions that have actually targeted the social capital of individuals or populations to improve health [3], partly due to a lack of understanding of factors determining the levels of social capital.

Evidence has also found that both individual and macro factors are associated with social capital. At the individual level, previous studies found that age $[19,20]$, gender [20], educational attainment [19-21], marital status [20,22], income [23, 24], and employment status $[19,23]$ were associated with social capital. However, the findings were not consistent; for example, Hanibuchi et al. [24] found that females showed lower general trust, while [20] found no gender differences in general trust. Moreover, macro-level variations in levels of social capital still exist after controlling for individual-level characteristics $[20,22,24-26]$. It is therefore necessary to examine the individual-level and macro-level determinants of social capital via multilevel study. Recently, several studies have also shown complex and contradictory associations between macro-level factors, including population density [27, 28], residential mobility [22], neighborhood walkability [24, 29-31], and streetscape greenery [32], and the level of social capital. Focus the interesting of current study, limited evidence has indicated that after controlling for individual characteristics, WSC was associated with work environment factors [33] such as, workplace demographics, employment patterns, work-unit size, psychosocial work environments [3437], such as leadership, organizational justice, including job strain and effort/reward imbalance. Oksanen, et al. found that smaller work-unit size and higher turnover were associated with higher WSC [33].

In addition, social capital may be influenced by cultural background [20]. Chinese Confucian values(CCVs), the common base of social culture in China is a complex system of moral, social, political, and religious thoughts with regard to an individual's relationships with others and appropriate conduct [38]. A cross-culture study indicated that the Chinese have highest level of collectivism and interpersonal trust among 42 countries [39] The concept most closely related to social capital is guanxi in Chinese culture, which refers to personal relationships, connections, or networks based on CCVs, which can potentially be utilized to acquire resources in informal and interpersonal forms [40]. These CCCs include xinyong (trustworthiness), mianzi (face), renqing (norms of interpersonal behavior), reciprocity, and obligation [41], which permeate all aspects of daily life in China. Theoretically, CCVs are distinctively about interpersonal relationships, while social capital is considered as both the attributes of individuals and organizations [42], so CCVs are different from social capital, but they are correlated; however, this has not been examined by formal study. Based on literature review, we hypothesize that WSC is associated with psychosocial work environment, CCVs after controlling for employee characteristics in Chinese workplace, and examine this hypothesis by a multilevel cross-sectional study.

\section{Study design and population Study population}

We conducted a cross-sectional study in Shanghai, China, from December 2016 to March 2017. In total, 2380 workers were randomly sampled through a two-stage sampling procedure. First, we selected 6 small workplaces (staff number $<100$ ), 18 medium workplaces $(100 \leq$ staff number $<300)$, and 10 large workplaces (staff number $\geq 100$ ) from the Pudong district of Shanghai using the convenience sampling method. In the second stage, we randomly sampled 100 workers from medium and large workplaces selected in the first stage; all workers from small workplace were included. Among 34 workplaces, there were 18 manufacturing enterprises, 8 service enterprises, 4 transport companies, 2 scientific institutions and 2 IT companies. A self-administered questionnaire was distributed via the Human Resources Department to all selected workers, who were provided written informed consents before filling in the questionnaires. Completion of the questionnaires was anonymous. The Institutional Review Board of the School of Public Health, Fudan University, approved the study.

\section{Measures}

Workplace social capital Workplace social capital was assessed with the validated Chinese version [43] of the WSC scale, which consists of eight 5-point Liker-scale items (from 1 to 5). Cronbach's alpha was 0.88 for the original scale and 0.95 for the current sample, indicating that the scale was acceptable. The items were as follows: (i) "We have a 'we are together' attitude"; (ii) "People feel understood and accepted by each other"; (iii) "People keep each other informed about work-related issues in the work unit"; (iv) "Members of the work unit build on each other's ideas in order to achieve the best possible outcome"; (v) "People in the work unit cooperate in order to help develop and apply new ideas"; (vi) "We can trust our supervisor"; (vii) "Our supervisor treats us with kindness and consideration"; and (viii) "Our supervisor shows concern for our rights as an employee." The mean score of the eight ratings was used to assess individual WSC. Higher score indicates higher level of individual WSC. 
Individual characteristics Besides gender, age (10-year categories), and marital status divided into married and unmarried(including divorce, widowed and single), we selected the following characteristics as indicators of socioeconomic status (SES): educational level (junior high school, senior high school, junior college, and college or higher), annual salary ( $<50,000$ yuan, 50,000-100,000 yuan, and $\geq 100,000$ yuan), years in the workplace ( 2 -year categories), and position (junior, intermediate, senior).

Psychosocial work environments Psychosocial work environments (PWEs) pertain to interpersonal and social interactions that influence behavior and development in the workplace [44]. The second short version of the Copenhagen Psychosocial Questionnaire (COPSOQ II) [45] was used to assess the following aspects of psychosocial work environment: (i) Work organization and job content, consisting of eight items scored from 1 to 5 to assess personal influence and possibilities for development. Cronbach's alpha was 0.91 for the present sample. (ii) Interpersonal relationships and leadership, consisting of 12 items scored from 1 to 5 to assess predictability, role clarity and conflicts, and quality of leadership. Cronbach's alpha was 0.94 for the present sample. (iii) Work-life balance, consisting of three items scored from 1 to 4 to assess job satisfaction and work-family conflict. Cronbach's alpha was 0.74 for the present sample. (iv) Workplace values, consisting of four items scored from 1 to 5 to assess trust regarding management and justice. Cronbach's alpha was 0.89 for the present sample. The mean scores of the corresponding items were used to assess PWEs. Higher score indicates the better psychosocial work environment, for example, the higher score of work-life balance indicates more balanced work-life.

Workplace Chinese confucian values In the current study, we focused on workplace Chinese Confucian values, which pertain to social norms with regards to building harmonious relationships at workplace. The Workplace Confucian Traditional Values scale [46] was used to assess four dimensions of workplace CCVs: respect for authorities (RA), altruism (AL), acceptance of authorities (AA), and the mianzi rule (MR). (i) RA was measured by the mean score of individual response to the following 6-point Likert items (from $1=$ strongly disagree to $6=$ strongly agree): "Following the advice of your elders is one of the best ways to avoid mistakes"; "When a dispute cannot be resolved, it should be done by the oldest colleague"; "A leader is like the head of the family, and the important thing in a company is to listen to his instructions"; "It is a virtue to respect and obey the leader." Cronbach's alpha was 0.84 for the present sample. (ii) AL was measured by the mean score of individual responses to the following 6 -point Likert items (from $1=$ strongly disagree to $6=$ strongly agree): "All requests of the department and company should be accepted unconditionally"; "Even if others are wrong, I should try my best to tolerate and forgive them"; "I should try not to inconvenience others, even if I was inconvenienced"; "While it is not good for yourself, it is always good to help others"; "Personal interests should be subordinated to the interests of the department and company." Cronbach's alpha was 0.81 for the present sample. (iii) AA was measured by the mean score of individual response to the following 6-point Likert items (from $1=$ strongly disagree to $6=$ strongly agree): "Employees should obey even the company rules that are wrong"; "An employee's salary should be firstly based on seniority, secondly based on individual ability"; "Employees should obey the rules and regulations of the company and not bother to understand the reason why they were established." Cronbach's alpha was 0.86 for the present sample. (iv) MR was measured by the mean score of individual responses to the following 6-point Likert items (from 1= strongly disagree to $6=$ strongly agree): "Mistakes are discussed alone, and virtues are stated openly"; "As long as the mianzi is passable, it's nothing to take a small loss"; "Even if you have conflicts of interest with your colleagues, you cannot easily tear mianzi." Cronbach's alpha was 0.80 for the present sample. Higher scores indicate higher level of individual perception of workplace CCVs.

All the above PWEs and workplace CCVs were assessed in two ways: (a) at the individual level, using each individual's own assessment; (b) at the aggregate level, summing up the assessments of all respondents from the same workplace. Both individual-level and aggregate-level PWEs and workplace CCVs were dichotomized into low and high by the median.

\section{Statistical analyses}

Descriptive statistics were performed firstly. Categorical variables were expressed as percentages and continuous variables were expressed as mean $(95 \% \mathrm{CI})$. Because the WSC scores (scored from 1 to 5) did not comprise a normal distribution, Mann-Whitney Tests for two groups' comparison and Kruskal-Wallis Tests for three or more groups' comparison were used. Literature reviewed indicated that macro-level variations in levels of social capital still exist after controlling for individual-level characteristics. It is therefore necessary to examine the individual-level and macro-level determinants of social capital via multilevel analysis. Our data had a multilevel structure consisting of employees (at level 1) nested within workplaces (at level 2), and the WSC scores (scored from 1 to 5) did not comprise a normal distribution, so we used multilevel ordinal regression models to examine the relationships of WSC with individual- and workplace-level variables. Individual-level variables were individual socioeconomic characteristics, individual-level PWEs, and individual-level workplace 
CCVs. Workplace-level variables were aggregate-level PEWs and workplace CCVs as well as workplace size (small, medium, or large). The analysis was conducted in following steps: Firstly, we examine the workplace-level variance in WSC without including any explanatory variables (not shown in Table 2); next, we examined the relationships of WSC with workplace-level variables (model 1); thirdly, we examined the relationships of WSC with individual-level variables (model 2); finally, we modeled all individual and workplace-level variables simultaneously (model 3). R version 3.3.3 [47] was used for all analyses. The multi-level analyses were performed using the lme4 package [48].

\section{Results}

As shown in Table 1, of the 2380 participants, more than half $(51.3 \%)$ were female, and most $(79.1 \%)$ were married. More than $60 \%$ (67.5\%) were aged $<40$ years old. About one quarter graduated from junior high school, and $22.6 \%$ graduated from college. More than half worked in medium workplaces; $11.9 \%$ had worked in the same workplace for less than 2 years, and $36.6 \%$ had worked in the same workplace for at least 10 years. The annual salary of $10 \%$ of participants was $\geq 100,000$ yuan, while that of $46.8 \%$ was $<50,000$ yuan. Only $5.1 \%$ of participants were in senior positions; most (68.6\%) held junior positions.

Univariate analyses showed that older age and more working years were associated with lower WSC (Table 1). With the exception of workplace size, high levels of PWEs were positively associated with a high level of WSC. For example, participants with high perceived work value had significantly higher WSC scores (mean: 4.23; 95\%CI: 4.20, 4.25) than those with low perceived work value (mean: 3.44; 95\%CI: 3.41, 3.48). As for workplace TCVs, participants with high AA perceived lower WSC (mean: 3.88; $95 \%$ CI: $3.85,3.91$ ) than their counterparts with low AA (mean: 3.95; 95\%CI: 3.90, 3.99). However, high RA, TA, and MR were positively correlated with high WSC.

The results of the multilevel ordinal regression models are shown in Table 2. The empty model (not shown in Table 2) indicated that there was significant variation in WSC across workplaces $\left(\chi^{2}=215.16, p<\right.$ 0.001 ); the interclass correlation coefficient (ICC) was 0.088 , indicating that $8.8 \%$ of the variance in WSC was explained by a random effect for workplaces.

The Model 1 indicated that there was no workplace-level variable (including PWEs and workplace size) associated with WSC (Table 2). The Model 2 including only individual-level variables, found that participants with senior high school, junior college and college or higher had lower level of WSC(B: $-0.260,-0.426$ and -0.365 respectively) compared with participants with junior high school, working years in the company were negatively associated with WSC (Table 2). Compared with participants under
30 years of age, those aged 40-49 had lower WSC (B: 0.272 ; $95 \% \mathrm{CI}$ : $-0.540,-0.003)$. After controlling for individual socioeconomic characteristics, all individual-level PWEs, RA, and TA (B ranged from 0.334 to 2.474) were positively associated with WSC, while high individual-level AA (B: -0.206 ; 95\%CI: $-0.372,-0.040$ ), and MR (B: 0.261 ; $95 \%$ CI: $-0.438,-0.084$ ) were negatively associated with WSC. Finally, all individual- and workplace-level variables were entered into the Model 3 simultaneously (Table 2). The associations between individual socioeconomic characteristics and WSC didn't change significantly. After controlling for individual socioeconomic characteristics, all individual-level PWEs, RA, and TA (B ranged from 0.325 to 2.467) were still positively associated with WSC, while high individual-level AA (B: -0.214; 95\%CI: - 0.381, $0.046)$ and MR (B: -0.258 ; 95\%CI: $-0.435,-0.080)$ were negatively associated with WSC; no workplace-level variable was still associated with WSC.

\section{Discussion}

Since social capital is one of the social determinants of population health and health-related behaviors, and the workplace is one of the main sources of social capital [3], it is important to explore the determinants of workplace social capital. This study found that higher education, favorable psychosocial work environments were positively associated with WSC, working years in the company was negatively associated with WSC, while workplace Chinese Confucian values had mixed relationships with WSC.

According to Huang's (2009) review, education not only inculcates knowledge and social responsibilities but also shapes values, such as reciprocity, respect, and trust. In the present study, we found that education level was positively associated with WSC, which is consistent with previous findings $[19,21,49]$. Because social capital is built over time, stable long-term employment is important for building WSC, which can be destroyed by the regular use of temporary employees [50]. However, we had an unexpected finding that a greater number of years spent working at a company was associated with lower WSC. This is partly consistent with a previous finding that higher proportion of temporary employees and higher employee turnover were associated with higher levels of WSC [26]. Social networks play a special role in a person's opportunity for mobility and provide better access to job information [51]. In China, nearly $61 \%$ of workers use social networks to search for work [52], and strong ties are frequently used [53]. In other words, new employees are social capitalists [26], who may gain the job in the current workplace by the social networks in the current workplace, and old employees with abundant social capital may switch to other companies. 
Table 1 Comparisons of workplace social capital among demographic characteristics by univariate analysis

\begin{tabular}{|c|c|c|c|c|c|c|c|}
\hline & & & & & & & \\
\hline Gender & & & & Hiah & $1536(645)$ & $400(397403)$ & \\
\hline Male & $1,158(48.7)$ & $3.90(3.86,3.94)$ & 0.7595 & Work values & & & \\
\hline Female & $1,222(51.3)$ & $3.90(3.87,3.94)$ & & Low & $986(41.4)$ & $3.44(3.41,3.48)$ & $<0.001$ \\
\hline Age & & & & High & $1,393(58.6)$ & $4.23(4.20,4.25)$ & \\
\hline$<30$ & $654(27.5)$ & $3.96(3.91,4.01)$ & 0.0120 & Respect for authorities & & & \\
\hline $30-39$ & $955(40.1)$ & $3.92(3.88,3.96)$ & & Low & $1,129(47.5)$ & $3.75(3.71,3.79)$ & $<0.001$ \\
\hline $40-49$ & $533(22.4)$ & $3.82(3.77,3.88)$ & & High & $1,250(52.5)$ & $4.04(4.01,4.07)$ & \\
\hline$\geq 50$ & $238(10.0)$ & $3.85(3.76,3.94)$ & & Altruism & & & \\
\hline Educational level & & & & Low & $1,166(49.0)$ & $3.74(3.71,3.78)$ & $<0.001$ \\
\hline Junior high school & $587(24.7)$ & $3.88(3.83,3.93)$ & 0.5621 & High & $1,213(51.0)$ & $4.06(4.02,4.09)$ & \\
\hline Senior high school & $724(30.4)$ & $3.88(3.83,3.93)$ & & Acceptance of authorities & & & \\
\hline Junior college & $530(22.3)$ & $3.91(3.86,3.97)$ & & Low & $860(36.1)$ & $3.95(3.90,3.99)$ & 0.0049 \\
\hline College or higher & $539(22.6)$ & $3.94(3.89,3.99)$ & & High & $1,520(63.9)$ & $3.88(3.85,3.91)$ & \\
\hline Marriage status & & & & Mianzi rule & & & \\
\hline Married & $1,883(79.1)$ & $3.93(3.87,3.98)$ & 0.1913 & Low & $822(34.5)$ & $3.86(3.82,3.90)$ & 0.0087 \\
\hline Unmarried & $497(20.9)$ & $3.89(3.87,3.92)$ & & High & $1,558(65.5)$ & $3.93(3.90,3.96)$ & \\
\hline
\end{tabular}

Annual salary (thousand yuan)

$\begin{array}{lll}<50 & 1,114(46.8) & 3.89(3.85,3.93) \\ 50-99 & 1,027(43.2) & 3.92(3.88,3.95) \\ \geq 100 & 239(10.0) & 3.89(3.82,3.97)\end{array}$

Working years

$\begin{array}{lll}<2 & 283(11.9) & 4.07(3.99,4.14) \\ 2-3 & 475(20.0) & 3.92(3.86,3.97) \\ 4-5 & 321(13.5) & 3.94(3.88,4.00) \\ 6-7 & 216(9.1) & 3.97(3.89,4.06) \\ 8-9 & 213(8.9) & 3.85(3.76,3.93) \\ \geq 10 & 872(36.6) & 3.82(3.78,3.87)\end{array}$

Position

$\begin{array}{lll}\text { Senior } & 121(5.1) & 3.86(3.73,3.40) \\ \text { Intermediate } & 621(26.1) & 3.94(3.90,3.99) \\ \text { Junior } & 1,638(68.6) & 3.89(3.86,3.92)\end{array}$

Workplace size

$\begin{array}{lll}\text { Small } & 220(9.2) & 3.92(3.83,4.01) \\ \text { Medium } & 1,258(52.9) & 3.92(3.88,3.95) \\ \text { Large } & 902(32.9) & 3.88(3.84,3.92)\end{array}$

Personal influence and development

$\begin{array}{lll}\text { Low } & 1,063(44.7) & 3.61(3.57,3.65) \\ \text { High } & 1,316(55.3) & 4.14(4.11,4.17)\end{array}$

Interpersonal relationships and leadership

$\begin{array}{llll}\text { Low } & 1,112(46.8) & 3.56(3.53,3.60) & <0.001 \\ \text { High } & 1,266(53.2) & 4.20(4.18,4.23) & \\ \text { Work-life balance } & & & \\ \text { Low } & 844(35.5) & 3.73(3.69,3.77) & <0.001\end{array}$

Table 1 Comparisons of workplace social capital among demographic characteristics by univariate analysis (Continued)

0.7941 An interesting finding of the present study was the favorable psychosocial work environments were positively associated with WSC. Previous studies also found that organizational justice, quality leadership and open communication $[35,36,54]$ were positively associated with WSC. A previous randomized intervention study among Chinese community health $(\mathrm{CHC})$ centers [55] indicated that team-building courses for $\mathrm{CHC}$ directors (team management, communication skills, and practical team leadership experiences) and group psychological consultations (on topics including team communications and stress management) for $\mathrm{CHC}$ staff can improve workplace social capital. There are at least two explanations for the associations between PWEs and WSC. First, favorable PWEs-such as higher personal influence and possibilities of development, open communication and role clarity, better interpersonal relationships and leadership, and higher work-life balance-may build harmonious social interactions and social cohesion $[36,56]$ and promote reciprocity, respect, and trust among employees, which are associated with bonding social capital. Second, quality leadership and organizational justice may promote open communication and connections across employees and employers to achieve common goals, and promote employees' trust for employers and managers, which is associated with bridging social capital.

According to Putnam, social capital "refers to the collective value of all 'social networks' and the inclinations that arise from these networks to do things for each other [57]." Cultural context may influence social capital. 
Table 2 The unstandardized coefficients and 95\% confidence intervals of multilevel ordinal regression models for workplace social capital-associated individual- and workplace-level variables

\begin{tabular}{|c|c|c|c|}
\hline & Model 1 & Model 2 & Model 3 \\
\hline \multicolumn{4}{|l|}{ Individual level variables } \\
\hline \multicolumn{4}{|l|}{ Gender } \\
\hline Male & & 0 & 0 \\
\hline Female & & $0.068(-0.093,0.229)$ & $0.058(-0.104,0.221)$ \\
\hline \multicolumn{4}{|l|}{ Age } \\
\hline$<30$ & & 0 & 0 \\
\hline $30-39$ & & $0.033(-0.183,0.249)$ & $0.007(-0.211,0.225)$ \\
\hline $40-49$ & & $-0.272(-0.540,-0.003)$ & $-0.313(-0.584,-0.042)$ \\
\hline$\geq 50$ & & $-0.125(-0.462,0.212)$ & $-0.155(-0.495,0.184)$ \\
\hline \multicolumn{4}{|l|}{ Educational level } \\
\hline Junior high school & & 0 & 0 \\
\hline Senior high school & & $0.260(0.047,0.472)$ & $0.260(0.047,0.473)$ \\
\hline Junior college & & $0.426(0.179,0.673)$ & $0.435(0.186,0.683)$ \\
\hline College or higher & & $0.365(0.082,0.647)$ & $0.403(0.116,0.691)$ \\
\hline \multicolumn{4}{|l|}{ Marriage status } \\
\hline Married & & 0 & 0 \\
\hline Unmarried & & $-0.024(-0.237,0.189)$ & $-0.040(-0.253,0.173)$ \\
\hline \multicolumn{4}{|c|}{ Annual salary (thousand yuan) } \\
\hline$<50$ & & 0 & 0 \\
\hline $50-100$ & & $-0.0001(-0.177,0.178)$ & $-0.006(-0.185,0.172)$ \\
\hline$\geq 100$ & & $-0.035(-0.343,0.274)$ & $-0.041(-0.352,0.270)$ \\
\hline \multicolumn{4}{|l|}{ Working years } \\
\hline$<2$ & & 0 & 0 \\
\hline $2-3$ & & $-0.414(-0.696,-0.132)$ & $-0.441(-0.724,-0.157)$ \\
\hline $4-5$ & & $-0.593(-0.903,-0.282)$ & $-0.618(-0.930,-0.306)$ \\
\hline $6-7$ & & $-0.418(-0.760,-0.077)$ & $-0.444(-0.786,-0.101)$ \\
\hline $8-9$ & & $-0.685(-1.038,-0.333)$ & $-0.704(-1.059,-0.348)$ \\
\hline$\geq 10$ & & $-0.622(-0.921,-0.323)$ & $-0.641(-0.942,-0.339)$ \\
\hline \multicolumn{4}{|l|}{ Position } \\
\hline Senior & & 0 & 0 \\
\hline Medium & & $-0.083(-0.443,0.277)$ & $-0.072(-0.433,0.289)$ \\
\hline Junior & & $-0.053(-0.402,0.296)$ & $-0.038(-0.388,0.312)$ \\
\hline \multicolumn{4}{|c|}{ Personal influence and development } \\
\hline Low & & 0 & 0 \\
\hline High & & $0.624(0.446,0.802)$ & $0.626(0.447,0.805)$ \\
\hline \multicolumn{4}{|c|}{ Interpersonal relations and leadership } \\
\hline Low & & 0 & 0 \\
\hline High & & $1.071(0.883,1.256)$ & $1.060(0.870,1.250)$ \\
\hline \multicolumn{4}{|l|}{ Work-life balance } \\
\hline Low & & 0 & 0 \\
\hline High & & $0.309(0.144,0.473)$ & $0.280(0.114,0.447)$ \\
\hline \multicolumn{4}{|l|}{ Work values } \\
\hline Low & & 0 & 0 \\
\hline
\end{tabular}


Table 2 The unstandardized coefficients and 95\% confidence intervals of multilevel ordinal regression models for workplace social capital-associated individual- and workplace-level variables (Continued)

\begin{tabular}{|c|c|c|c|}
\hline & Model 1 & Model 2 & Model 3 \\
\hline High & & $2.474(2.259,2.689)$ & $2.467(2.251,2.683)$ \\
\hline \multicolumn{4}{|c|}{ Respect to authorities } \\
\hline Low & & 0 & 0 \\
\hline High & & $0.334(0.144,0.524)$ & $0.325(0.134,0.516)$ \\
\hline \multicolumn{4}{|l|}{ Altruism } \\
\hline Low & & 0 & 0 \\
\hline High & & $0.357(0.165,0.549)$ & $0.347(0.155,0.539)$ \\
\hline \multicolumn{4}{|c|}{ Acceptance of authorities } \\
\hline Low & & 0 & 0 \\
\hline High & & $-0.206(-0.372,-0.040)$ & $-0.214(-0.381,-0.046)$ \\
\hline \multicolumn{4}{|l|}{ Mianzi rule } \\
\hline Low & & 0 & 0 \\
\hline High & & $-0.261(-0.438,-0.084)$ & $-0.258(-0.435,-0.080)$ \\
\hline \multicolumn{4}{|c|}{ Workplace-level variables } \\
\hline \multicolumn{4}{|c|}{ Workplace size } \\
\hline Small & 0 & & 0 \\
\hline Medium & $-0.019(-0.468,0.431)$ & & $0.114(-0.310,0.539)$ \\
\hline Large & $-0.247(-0.787,0.293)$ & & $0.205(-0.303,0.713)$ \\
\hline \multicolumn{4}{|c|}{ Personal influence and development } \\
\hline Low & 0 & & 0 \\
\hline High & $0.278(-0.156,0.712)$ & & $-0.182(-0.596,0.232)$ \\
\hline \multicolumn{4}{|c|}{ Interpersonal relations and leadership } \\
\hline Low & 0 & & 0 \\
\hline High & $0.129(-0.242,0.500)$ & & $0.182(-0.173,0.536)$ \\
\hline \multicolumn{4}{|c|}{ Work-life balance } \\
\hline Low & 0 & & 0 \\
\hline High & $0.208(-0.105,0.520)$ & & $0.141(-0.150,0.434)$ \\
\hline \multicolumn{4}{|l|}{ Work values } \\
\hline Low & 0 & & 0 \\
\hline High & $0.332(-0.102,0.766)$ & & $0.370(-0.035,0.774)$ \\
\hline \multicolumn{4}{|c|}{ Respect for authorities } \\
\hline Low & 0 & & 0 \\
\hline High & $-0.081(-0.575,0.413)$ & & $0.093(-0.373,0.559)$ \\
\hline \multicolumn{4}{|l|}{ Altruism } \\
\hline Low & 0 & & 0 \\
\hline High & $0.082(-0.475,0.640)$ & & $-0.329(-0.844,0.186)$ \\
\hline \multicolumn{4}{|c|}{ Acceptance of authorities } \\
\hline Low & 0 & & 0 \\
\hline High & $0.007(-0.299,0.313)$ & & $-0.038(-0.322,0.246)$ \\
\hline \multicolumn{4}{|l|}{ Mianzi rule } \\
\hline Low & 0 & & 0 \\
\hline High & $0.387(-0.111,0.884)$ & & $0.154(-0.310,0.539)$ \\
\hline
\end{tabular}


In Asian countries, for example, the Chinese have very high levels of general trust and trust in the social system, while the Japanese have high general trust but very low trust in the social system [58]. Although researchers have argued that social capital is similar to guanxi, which is one of the main traditional values in China [41, 42], in this study, we found the surprising result that traditional Chinese workplace values have both positive and negative effects on WSC. Respect for authority (RA) and altruism (TA) were positively associated with WSC, while acceptance of authority and the mianzi rule were negatively associated with WSC. Workplace Chinese Confucian values aim to create harmonious interpersonal relationships, so employees may accept authorities' (employers' and managers') decisions and demands, even when those are bad for the individual [46]. The mianzi rule [59] involves employees taking care of the social reputations of themselves, colleagues, and leaders to maintain and promote their social reputation in a variety of ways; this may require employees to do some things they do not want to do, such as accepting authorities' decisions. Thus, acceptance of authorities and the mianzi rule do not constitute real trust, only superficial social manners, which may deteriorate social capital in the workplace.

\section{Limitations}

Several limitations of this study should be noted. First, as is inherent in any cross-sectional study, the ability to draw causal inferences from the associations of workplace psychosocial factors and traditional Chinese workplace values with workplace social capital is substantially limited. Although we attempted to control for confounders, we cannot be certain that we have controlled for all possible confounders. For example, [26] found that workplace social capital was negatively associated with a high proportion of manual and male employees, job demand, which were not included in this study. Second, we tried to include a variety of workplaces, but this is not a representative sample incurring by selection bias, which may weaken both internal and external validity. We also could not survey employees who had resigned, whose status-including PWEs, workplace CCVs, and workplace social capital-may be different from that of the participants we surveyed in this study. Third, workplace social capital may be affected by factors outside workplaces that we did not assess in this study. For example, we found that high work-life balance was positively associated with workplace social capital, which suggests that family and personal life factors may affect workplace social capital. Longitudinal studies investigating the links between varied workplace psychosocial factors and workplace social capital among workers from varied industries would be worth conducting in the future.

\section{Conclusion}

Despite some limitations, to the best of our knowledge, this is the first study to examine the associations between psychosocial work environments and workplace social capital in a Chinese context. Our study provides additional evidence that favorable psychosocial work environments-including personal development, leadership, work-life balance, and work value-is positively associated with workplace social capital, while workplace Chinese Confucian values have both positive and negative associations with workplace social capital. These findings suggest that workplace social capital associates with multiple factors. Psychosocial work environments and cultural context are important in understanding variations in workplace social capital between individuals.

\section{Abbreviations \\ AA: Acceptance of authorities; AL: Altruism; CCVs: Chinese Confucian values; CHC: Chinese community health; COPSOQ II: The second short version of the Copenhagen Psychosocial Questionnaire; MR: Mianzi rule; PWEs: Psychosocial work environments; RA: Respect for authorities; SES: Socioeconomic status; WSC: Workplace social capital}

\section{Acknowledgements}

We would like to thank the study participants, reviewers and editors.

\section{Funding}

This work was funded by the National Natural Science Foundation of China (grant no. 71573048) and partially supported by the Key Project of the Fourth-Round Three-Year Plan of Action on Public Health in Shanghai (grant no. 15GWZK1001). The funding bodies had no role in the design of the study, data collection, analyses, interpretation of data, writing of the manuscript, or the decision to publish.

\section{Availability of data and materials}

The data that support the findings of this study are available from the corresponding author, Dr. Junling Gao. Email: jlgao@fudan.edu.cn

\section{Authors' contributions}

All authors took part in the study design, JLG has analyzed, interpreted and written the manuscript. JW, DLY, YKZ recruited study participants, supported $J \mathrm{LG}$ to analysis and interpreted the data. HF and JMD supervised the revision of the manuscript. All authors revised and approved the final manuscript.

Ethics approval and consent to participate

Ethical approval was obtained from The Institutional Review Board of the School of Public Health, Fudan University.

Consent for publication

Not-applicable.

Competing interests

Junling Gao is an Associate Editor for BMC Public Health. The authors declare that they have no competing interests.

\section{Publisher's Note}

Springer Nature remains neutral with regard to jurisdictional claims in published maps and institutional affiliations. 


\section{Author details}

'School of Public Health, Fudan University; Fudan Health Communication Institute, PO Box 248, 138 Yixueyuan Road, Shanghai 200032, China. Pudong Center of Disease Control and Prevention, Shanghai 200136, China.

\section{Received: 20 February 2018 Accepted: 27 July 2018 \\ Published online: 06 August 2018}

\section{References}

1. Kawachi I, Subramanian SV, Kim D. Social capital and health. New York: Springer; 2008

2. Murayama H, Fujiwara Y, Kawachi I. Social capital and health: a review of prospective multilevel studies. J Epidemiol. 2012;22(3):179-87.

3. Kawachi I, Takao S, Subramanian SV. Global perspectives on social capital and health. New York: Springer; 2013.

4. Kouvonen A, Kivimaki M, Vahtera J, Oksanen T, Elovainio M, Cox T, Virtanen M, Pentti J, Cox SJ, Wilkinson RG. Psychometric evaluation of a short measure of social capital at work. BMC Public Health. 2006:6:251.

5. Kawachi I. Social capital and community effects on population and individual health. Ann N Y Acad Sci. 1999:896:120-30.

6. Li S, Horner P, Delva J. Social capital and cigarette smoking among Latinos in the United States. Subst Abuse Rehabil. 2012;3:83-92.

7. Li S, Delva J. Social capital and smoking among Asian American men: an exploratory study. Am J Public Health. 2012;102(Suppl 2):S212-21.

8. Oksanen T, Kawachi I, Kouvonen A, Suzuki E, Takao S, Sjosten N, Virtanen M, Pentti J, Vahtera J, Kivimaki M. Workplace social capital and adherence to antihypertensive medication: a cohort study. PLoS One. 2011;6(9):e24732.

9. Vaananen A, Kouvonen A, Kivimaki M, Oksanen $T$, Elovainio M, Virtanen M, Pentti J, Vahtera J. Workplace social capital and co-occurrence of lifestyle risk factors: the Finnish public sector study. Occup Environ Med. 2009;66(7):432-7.

10. Gao J, Nehl EJ, Fu H, Jia Y, Liu X, Zheng P. Workplace social capital and smoking among Chinese male employees: a multi-level, cross-sectional study. Prev Med. 2013;57(6):831-6.

11. Kouvonen A, Oksanen T, Vahtera J, Vaananen A, De Vogli R, Elovainio M, Pentti J, Leka S, Cox T, Kivimaki M. Work-place social capital and smoking cessation: the Finnish public sector study. Addiction. 2008;103(11):1857-65.

12. Almedom AM. Social capital and mental health: an interdisciplinary review of primary evidence. Soc Sci Med. 2005;61(5):943-64.

13. Gao J, Weaver SR, Dai J, Jia Y, Liu X, Jin K, Fu H. Workplace social capital and mental health among Chinese employees: a multi-level, cross-sectional study. PLoS One. 2014;9(1):e85005.

14. Sakuraya A, Imamura K, Inoue A, Tsutsumi A, Shimazu A, Takahashi M, Totsuzaki T, Kawakami N. Workplace social capital and the onset of major depressive episode among workers in Japan: a 3-year prospective cohort study. J Epidemiol Community Health. 2017;71(6):606-12.

15. Pattussi MP, Olinto MT, Canuto R, da Silva GA, Paniz VM, Kawachi I. Workplace social capital, mental health and health behaviors among Brazilian female workers. Soc Psychiatry Psychiatr Epidemiol. 2016;51(9): 1321-30

16. Oksanen T, Kivimaki M, Kawachi I, Subramanian SV, Takao S, Suzuki E, Kouvonen A, Pentti J, Salo P, Virtanen M, et al. Workplace social capital and all-cause mortality: a prospective cohort study of 28,043 public-sector employees in Finland. Am J Public Health. 2011;101(9):1742-8.

17. Hawe P, Shiell A. Social capital and health promotion: a review. Soc Sci Med. 2000;51(6):871-85.

18. Eriksson M. Social capital and health--implications for health promotion. Glob Health Action. 2011:4:5611.

19. Lindstrom M, Merlo J, Ostergren PO. Individual and neighbourhood determinants of social participation and social capital: a multilevel analysis of the city of Malmo, Sweden. Soc Sci Med. 2002;54(12):1779-91.

20. Kaasa A, Parts E. Individual-level determinants of social Capital in Europe: differences between country groups. Acta Sociol. 2008;51(2):145-68.

21. Huang J, Maassen van den brink H, Groot W. A meta-analysis of the effect of education on social capital. Econ Educ Rev. 2009:28(4):454-64.

22. Neutens T, Vyncke V, De Winter D, Willems S. Neighborhood differences in social capital in Ghent (Belgium): a multilevel approach. Int J Health Geogr. 2013;12:52.

23. Groot $W$, van den Brink HM, van Praag $B$. The compensating income variation of social capital. Soc Indic Res. 2007;82(2):189-207.
24. Hanibuchi T, Kondo K, Nakaya T, Shirai K, Hirai H, Kawachi I. Does walkable mean sociable? Neighborhood determinants of social capital among older adults in Japan. Health Place. 2012;18(2):229-39.

25. Subramanian SV, Lochner KA, Kawachi I. Neighborhood differences in social capital: a compositional artifact or a contextual construct? Health Place. 2003:9(1):33-44

26. Oksanen T, Kawachi I, Kouvonen A, Takao S, Suzuki E, Virtanen M, Pentti J, Kivimaki M, Vahtera J. Workplace determinants of social capital: crosssectional and longitudinal evidence from a Finnish cohort study. PLoS One. 2013;8(6):e65846.

27. Nguyen D. Evidence of the impacts of urban sprawl on social capital. Environ Plann B Plann Des. 2010;37(4):610-27.

28. Brueckner JK, Largey AG. Social interaction and urban sprawl. J Urban Econ. 2008;64(1):18-34.

29. Leyden KM. Social capital and the built environment: the importance of walkable neighborhoods. Am J Public Health. 2003;93(9):1546-51.

30. Wood L, Frank LD, Giles-Corti B. Sense of community and its relationship with walking and neighborhood design. Soc Sci Med. 2010;70(9):1381-90.

31. du Toit L, Cerin E, Leslie E, Owen N. Does walking in the Neighbourhood enhance local sociability? Urban Stud. 2007:44(9):1677-95.

32. de Vries S, van Dillen SM, Groenewegen PP, Spreeuwenberg P. Streetscape greenery and health: stress, social cohesion and physical activity as mediators. Soc Sci Med. 2013:94:26-33.

33. Oksanen T, Kawachi I, Kouvonen A, Takao S, Suzuki E, Virtanen M, Pentti J, Kivimäki M, Vahtera J. Workplace determinants of social capital: crosssectional and longitudinal evidence from a Finnish cohort study. PLoS One. 2013;8(6):e65846.

34. Oksanen $T$, Kawachi I, Jokela M, Kouvonen A, Suzuki E, Takao S, Virtanen M, Pentti J, Vahtera J, Kivimaki M. Workplace social capital and risk of chronic and severe hypertension: a cohort study. J Hypertens. 2012;30(6):1129-36.

35. Oshio T, Inoue A, Tsutsumi A. The mediating and moderating effects of workplace social capital on the associations between adverse work characteristics and psychological distress among Japanese workers. Ind Health. 2014;52(4):313-23.

36. Materne M, Henderson A, Eaton E. Building workplace social capital: a longitudinal study of student nurses' clinical placement experiences. Nurse Educ Pract. 2017;26:109-14.

37. Lindstrom M, Malmo Shoulder-neck Study G. Psychosocial work conditions, social participation and social capital: a causal pathway investigated in a longitudinal study. Soc Sci Med. 2006;62(2):280-91.

38. Gao E, Zuo X, Wang L, Lou C, Cheng Y, Zabin LS. How does traditional Confucian culture influence Adolescents' sexual behavior in three Asian cities? J Adolesc Health. 2012;50(3):S12-7.

39. Allik J, Realo A. Individualism-collectivism and social capital. J Cross-Cult Psychol. 2004:35(1):29-49.

40. Ruan J. Guanxi and Social Capital. In: Guanxi, Social Capital And School Choice In China: The Rise Of Ritual Capital. Cham: Springer International Publishing; 2017. p. 37-73.

41. Qi X. Guanxi, social capital theory and beyond: toward a globalized social science. Br J Sociol. 2013;64(2):308-24

42. Huang. How Guanxi Relates to Social Capital? A Psychological Perspective. J Soc Sci. 2011;7(2):120-6.

43. Gao J, Jia Y, Wu X, Li G, Dai J, Fu H. An exploratory study on relationship between social capital and health in workplace. Chin J Health Educ. 2012:28:806-9.

44. Jacobs K, Hellman M, Markowitz J, Wuest E. Psychosocial Work Environment. In: Gellman MD, Turner JR, editors. Encyclopedia of Behavioral Medicine. New York: Springer New York; 2013. p. 1587.

45. Pejtersen JH, Kristensen TS, Borg V, Bjorner JB. The second version of the Copenhagen psychosocial questionnaire. Scand J Public Health. 2010;38(3 Suppl):8-24

46. Wang Q, Zhang J. Confucian Traditional Values at Workplace: Theory, Measurement and Validation. Nankai Bus Rev. 2012;15(4):66-79.

47. R Core Team. R version 3.3 .3 (2017-03-06) -- "Another Canoe", The R Foundation for Statistical Computing Platform: x86_64-w64-mingw32/x64 (64-bit). Vienna: R Foundation for Statistical Computing; 2017.https://www.rproject.org/.

48. Bates D, Mächler M, Bolker B, Walker S. Fitting linear mixed-effects models using Ime4. J Stat Softw. 2015;67(1):1-48.

49. Yang QQ Qina SU. Analysis on the Impact Factors in the Formation of Social Capital in China. East China Econ Manage. 2012;26(3):-69, 76. 
50. Leana CR, Van Buren HJ. Organizational social capital and employment practices. Acad Manag Rev. 1999;24(3):538-55.

51. Granovetter M. The strength of weak ties: a network theory revisited. Sociol Theory. 1983;1:201-33.

52. Bian Y, Huang X. Beyond the strength of social ties. Am Behav Sci. 2015; 59(8):961-76.

53. Bian Y. Bringing strong ties back in: indirect ties, network bridges, and job searches in China. Am Sociol Rev. 1997;62(3):366-85.

54. Kohler T, Janssen C, Plath SC, Reese JP, Lay J, Steinhausen S, Gloede T, Kowalski C, Schulz-Nieswandt F, Pfaff H. Communication, social capital and workplace health management as determinants of the innovative climate in German banks. Int J Public Health. 2010;55(6):561-70.

55. Sun X, Zhang N, Liu K, Li W, Oksanen T, Shi L. Effects of a randomized intervention to improve workplace social capital in community health centers in China. PLoS One. 2014:9(12):e114924.

56. Norikoshi K, Kobayashi T, Tabuchi K. A qualitative study on the attributes of nurses' workplace social capital in Japan. J Nurs Manag. 2018;26(1):74-81.

57. Putnam RD, Leonardi R, Nonetti RY. Making democracy work:civic traditions in modern. Italy: Princeton University Press; 1994.

58. Inoguchi T. Social Capital in Ten Asian Societies. In: Inoguchi T, Tokuda Y, editors. Trust with Asian Characteristics: Interpersonal and Institutional. Singapore: Springer Singapore; 2017. p. 13-28.

59. Hwang K. Face and favor: the Chinese power game. Am J Sociol. 1987;92(4): 944-74

Ready to submit your research? Choose BMC and benefit from:

- fast, convenient online submission

- thorough peer review by experienced researchers in your field

- rapid publication on acceptance

- support for research data, including large and complex data types

- gold Open Access which fosters wider collaboration and increased citations

- maximum visibility for your research: over $100 \mathrm{M}$ website views per year

At BMC, research is always in progress.

Learn more biomedcentral.com/submissions 